4 rows of cells. In the tissues of the lung acinus, alizarin granules appear that mark the localization of calcium cations.

Table 1.

$\begin{array}{lll}\text { Indicator } & \text { Control group } & \text { Hypogravity group } \\ \text { ACC } & 1,1 \pm 0,16 & 0,3 \pm 0,14 p<0,05\end{array}$

Under the influence of hypogravitation on the body of rats, the histochemical reaction is sharply weakened (Table 1). Under the influence of hypogravitation in rats, in most fields of view of the microscope on the lung slices there is a lack of response. In the field of view, single deposits of disintegrated large granules of the reaction product were observed, or small granules $0,2 \mu \mathrm{m}$ in diameter to $0,5 \mu \mathrm{m}$, their amorphous accumulations have a length and a width of less than 5-10 $\mu \mathrm{m}$. In the control group of animals, in the field of view of the microscope, foci of coarse accumulations of alizarin sediment appear, represented by small granules $0.2 \mu \mathrm{m}$ in diameter to $0,5 \mu \mathrm{m}$; they form irregularly shaped zones of alizarin precipitation with a length of 5 to $15 \mu \mathrm{m}$. Separated large granules of the reaction product are noted, in an amount from 5 to 50 , the diameter of the granules is from $0,2 \mu \mathrm{m}$ to $2 \mu \mathrm{m}$.

Conclusion: Experimental hypogravity of the organism has a significant effect on calcium metabolism in rat lungs.

Literature

1. Ilyin E.A., Novikov V.E. A bench for modeling physiological effects of weightlessness in laboratory experiments with rats // Kosm. biol. and air-medicines. 1980. Vol. 24. № 3. P. 79-80.

2. Zinoviev S.V. Histochemical characteristics of the venous bed of the respiratory department of light experimental animals subjected to chronic supercooling after administration of dihydroquercetin into the organism // Bulletin of physiology and pathology of Respiration. 2012. № 45. P. 57-61.

UDC: 616.24-008.444-072.7 DOI 10.22448/AMJ.2017.3.110-111

\title{
THE SNORE PHENOMENON AT CHILDREN
}

\section{A.A. Blotskiy, V.V. Antipenko, R.A. Blotskiy}

\section{Amur State Medical Academy, Blagoveshchensk, Russia}

Abstrakt. The article gives the reasons for the occurrence of snoring in children. The prevalence of snoring in children in the city of Blagoveshchensk and the Amur Region has been studied. The phenomenon of snoring is revealed in $29 \%$ of children. The authors proposed surgical and conservative options for correcting the phenomenon of snoring. The effectiveness of the techniques reached $86-89 \%$.

Key words: Phenomenon of snoring, obstructive sleep apnea, children.

The snore is known to be the acoustic phenomenon developing in the result of vibration of oropharyngel structures during inhalation in incomplete obstruction of the upper respiratory tract. It occurs in 43 \%of cases of adults. The presence of rhino - and stomatopharyngel hypertrophy in children contribute to the air space decrees of the latters and to appearance of snore phenomenon and syndrome of obstructive sleepy apnoë (SOSA) syndrome. In our literature there are no date touching upon the problems of children's snore in different age groups. There are only some observation on the limited number of patients which do not reflect the importance of this problem.

Determination of epidemiology and prevalence of different chronic disorders contributing to the development of snore in children and elimination it's clinical manifestation with the help of surgical and conservative methods of treatment in the urgent problem at present.

Questionaire among 860 children in different age groups in Blagoveshensk and Amur region was held to study the epidemiology of child snore in different aged groups and to plan special medical aid. It was determined that $29 \%$ of cases of asked children suffer from snore phenomenon, of them $0,6 \%$ suffer from snore phenomenon till the 1 year of age; $22,7 \%$ - till the 1-3 years of age; $28,7 \%$ - till the $4-6$ years of age; $30,3 \%$ - till the $7-11$ years of age; $6,8 \%$ - till the $12-14$ years of age; $10,9 \%$ till the 15-18 years of age. The syndrome of obstructive sleepy apnoë was found in 12 (4,8\%) children suffering from snore.

Of all questionaired children chronic disorders of nasopharyngel organs were revealed in $41,2 \%$ of cases, of them in $290(81,7 \%)$ children chronic disorders of nasopharyngel organs contributed to the development of snore phenomenon. Patients who are older then 10 years with the purpose of diagnostics of anatomy-physiological preconditions of development of snore and syndrome of obstructive sleepy apnoë was carried out a magnetic-resonance tomography.

$72 \%$ of the revealed patients with snore phenomenon and all patients with SOSA were performed surgical and conservative treatment aimed at the elimination of predisposed factors and pathologic processes in nasal cavity, perirhinal sinuses, pharynx and larynx, contributing to the development of the pathology given.

Surgical treatment allowed to eliminate of snore and SOSA in $86,4 \%$ of cases in different aged groups of patients. 
Conservative therapy in patients with hypertrophy o lymphadenoid pharynx tissue including both the traditional and antioxydant therapy with the use of different kinds of low intensive lases promoted the elimination of this pathology in $89,2 \%$ of cases of patients.

Thus, children suffering from severe form of snore phenomenon and SOSA belongs to the risk group according to the syndrome of sudden death.

Questionary conducted enabled to reveal a group of such patients and direct them for the specialized treatment during which predisposed factors contributing to the development of the given pathology had been eliminated.

Literature:

1. Blotskiy A.A. Surgery treatment phenomenon of snoring and obstructive sleep apnea // Sovremene technology технологии.- 2001.-№ 3.-С. 38 - 42.

2. Blotskiy A.A., Pluzhnikov M.S. Phenomenon of snoring and obstructive sleep apnea. -SPb.:Spec. Lit., 2002. -176 c.

3. Blotskiy A.A., Pluzhnikov M.S. Primenenie Nd:YAG - laser of treatment phenomenon of snoring and obstructive sleep apnea //Folia otorhinolaryngologiae et Pathologiae Respiratoriae. - 2002. - Vol. 7. - № 1-2 . -C. 35-40.

4. Blotskiy A.A., Pluzhnikov M.S. Clinical analyses phenomenon of snoring and obstructive sleep apnea laser uvulopalathoplasty // Rossiskaiy rinolodgy. - 2002. - № 3. -C. 27-35.

5. Blotskiy A.A.., Deniskin O.N. Magnetic-resonance tomography diagnostic anatomical orofaryngial of the phenomenon of snoring and obstructive sleep apnea // Folia otorhinolaryngologiae et Pathologiae Respiratoriae. - 2004. - Vol. 10. - № 3-4. -C. 33-37.

6. Blotskiy A.A.., Rubis I.A. Epidemiology phenomenon of snoring and obstructive sleep apnea at children of the treatment chronic diseases of nasopharyngel organs // Folia otorhinolaryngologiae et Pathologiae Respiratoriae. - 2005. - Vol. 11. - № 1-2. - C.21-24.

7. Blotskiy A.A.., Rubis I.A. Antioxydant therapy diseases chronic tonsillitis at children of phenomenon of snoring and obstructive sleep apnea // Materials regions conference otorinolaryngology "Actual questions otorinolarungology». Blagoveshchensk. - 2006. -C. 66-69.

8. Blotskiy A.A., Pluzhnikov M.S. obstructive sleep apnea // Vestnik otorinolaringplogii. - 2008. - №4. -C.78-80.

9. Pluzhnikov M.S., Blotskiy A.A. Epidemiology phenomenon chronic diseases of nasopharyngel organs of snoring and obstructive sleep apnea of the leaser treatment // Vestnik otorinolaringplogii..-2002.-№3.-C. 12-15.

UDC 616.151.5-08-039.72 DOI 10.22448/AMJ.2017.3.111-113

\title{
ANALYSIS OF THE EFFICIENCY OF DABIGATRAN AND RIVAROXABAN PREPARATIONS WITH HEREDITARY HEMATOGE- NOUS THROMBOPHILIA
}

\author{
V.V. Voitsekhovsky, Yu.V. Suslova
}

\section{Amur State Medical Academy, Russia, Blagoveshchensk}

Summary The analysis of the cases of clinical manifestation and the effectiveness of secondary antithrombotic therapy in patients observed in the hematological office of the Amur regional polyclinic with the diagnosis of "hereditary hematogenic thrombophilia" was carried out. In most cases, the first manifestation of hereditary hematogenous thrombophilia is thromboembolism of the pulmonary artery $(60 \%)$. The young age of the patient, hereditary history of thrombosis, the absence of provoking factors for the development of thrombosis is the basis for examination for thrombophilia. Warfarin, long used as an antithrombotic therapy, has a large number of disadvantages. Drugs dabigatran and rivaroxaban are effective and safe preparations of secondary prevention of thrombosis and can be used in hereditary hematogenous thrombophilia. Absence of the need for constant laboratory monitoring and extremely rare hemorrhagic complications make it possible to use them in patients living in regions remote from large medical centers.

Keywords: hematogenous hereditary thrombophilia, thrombosis prevention

Under the term "hematogenous thrombophilia" Z.S. Barkagan understood all hereditary (genetically conditioned), and acquired (secondary, symptomatic) hemostasis disorders, which are prone to early onset and recurrence of thrombosis, thromboembolism, ischemia and infarction of organs [1]. WHO and the International Society for Thrombosis and Hemostasis (ISTH) in 1995 identified hereditary thrombophilia as an unusual incidence of thrombosis with an early age onset, a family history, a severity of thrombosis disproportionate to the known causative factor and episodes of recurrent thrombosis [11]. In 2008, the American College of Thoracic Doctors for antithrombotic and thrombolytic therapy defined thrombophilia as one or more of the following symptoms: deficiency of antithrombin, protein $\mathrm{C}$, protein $\mathrm{S}$, resistance to activated protein $\mathrm{C}$, mutation factor $\mathrm{V}$ Leiden, prothrombin mutation G20210A, hyperhomocysteinemia, homozygous carriage A thermolabile variant of methylenetetrahydrofolate reductase, antiphospholipid antibodies, an increase in the activity of factor VIII, or a decreased level of protein Z [6].

Hereditary hematogenous thrombophilia is characterized by: early manifestation, the absence of an obvious provocative factor and a single universal diagnos- 